Article

\title{
Effect of Wheat Bran on Fecal Butyrate-Producing Bacteria and Wheat Bran Combined with Barley on Bacteroides Abundance in Japanese Healthy Adults
}

\author{
Seiichiro Aoe ${ }^{1, *}$, Fumiko Nakamura ${ }^{2}$ and Suguru Fujiwara ${ }^{2}$ \\ 1 Department of Food Science, Faculty of Home Economics, Otsuma Women's University, 12 Sanban-cho, \\ Chiyoda-ku, Tokyo 102-8357, Japan \\ 2 CPCC Company Limited, 3-3-5 Uchikanda, Chiyoda-ku, Tokyo 101-0047, Japan; \\ f.nakamura@cpcc.co.jp (F.N.); s.fujiwara@cpcc.co.jp (S.F.) \\ * Correspondence: s-aoe@otsuma.ac.jp; Tel.: +81-3-5275-6048
}

Received: 2 November 2018; Accepted: 11 December 2018; Published: 14 December 2018

check for updates

\begin{abstract}
Wheat bran (WB) is rich in insoluble arabinoxylan, while BARLEYmax (BM) is a barley line that is rich in fructan, resistant starch, and $\beta$-glucan. In the present study, we investigated which of these two fiber sources would produce more favorable changes in the fecal variables of healthy subjects. Sixty healthy subjects were randomly divided into four groups ( $n=15$ per group) and fed twice daily for 4 weeks with baked cereal bars containing neither WB nor BM (WB-BM-), $\mathrm{WB}$ without $\mathrm{BM}(\mathrm{WB}+\mathrm{BM}-), \mathrm{BM}$ without $\mathrm{WB}(\mathrm{WB}-\mathrm{BM}+)$, or $\mathrm{WB}$ and $\mathrm{BM}(\mathrm{WB}+\mathrm{BM}+)$. At baseline and after 4 weeks, the fecal microbiota composition and the concentrations of short-chain fatty acids were measured. A significant interactive effect of WB and BM on the abundance of genus Bacteroides was observed at week 4 . The abundance of butyrate-producing bacteria and the fecal concentration of $n$-butyrate were significantly higher in the $\mathrm{WB}+$ groups than in the $\mathrm{WB}-$ groups. In conclusion, WB was associated with elevated fecal concentrations of short-chain fatty acids including butyrate owing to an increase in the abundance of butyrate-producing bacteria. Additionally, the combination of WB and BM was associated with an increase in the abundance of genus Bacteroides. Therefore, both WB alone and WB combined with BM favorably influenced the fecal variables of healthy subjects.
\end{abstract}

Keywords: wheat bran; BARLEYmax; fecal butyrate; butyrate producer; Bacteroides

\section{Introduction}

Epidemiological studies have reported that the consumption of whole grain cereals or cereal brans may reduce intestinal transit time, increase the bacterial fermentation of fiber to short-chain fatty acids (SCFAs) with anticarcinogenic properties, and thereby reduce the risk of colorectal cancer [1-3]. A recent systematic review concluded that high-fiber, wheat-based cereals can improve bowel function with grade A evidence (i.e., can be trusted to guide clinical practice) [4].

The mechanisms through which fiber can improve bowel function remain to be fully elucidated. One possible mechanism proposed by Sonnenburg et al. [5] is that microbiota-accessible carbohydrates found in dietary fiber may substantially influence the microbial ecosystem in the gut. They showed that a diet low in such carbohydrates resulted in a progressive loss of microbiota diversity, which is a type of dysbiosis. Other possible forms of dysbiosis include (i) an expansion of pathobionts; (ii) a change in the microbial composition, i.e., an increase or reduction in the abundance of an indicator species; and (iii) a change in microbial functional capacity [6]. It is considered that a diet high in fat and low in fermentable dietary fiber shifts the microbiota toward a more dysbiotic pattern associated with an increased risk of intestinal inflammation [7]. 
Wheat bran (WB) is a promising fiber source that is rich in insoluble fiber (35.0-48.4 $\mathrm{g} / 100 \mathrm{~g}$ ) [8] and arabinoxylan (22-30 g/100 g), which is an almost-insoluble fiber linked with ferulic acid [9]. A systematic review concluded that insoluble fiber (WB) showed favorable results for the treatment of irritable bowel disease [10]. It has also been reported that WB induced a significant increase in fecal bulk, a reduction in intestinal transit time, and a significant increase in the frequency of bowel movements in healthy people [11]. The structures of WB and the aleurone fraction of wheat have rarely been mentioned or characterized in interventional studies [12]. The structure of a food product containing these fractions can markedly affect the bioavailability of bioactive compounds and nutrients, thus influencing their effects on metabolism and health. The modification of WB and aleurone fractions by baking can influence their effects on the colon by altering the fermentation of their dietary fiber components. SCFAs such as acetate, propionate, and butyrate are important metabolites of microbial fermentation, and butyrate has been suggested to potentially exert effects on health [9]. Recent reports have shown that arabinoxylan in WB is the main component responsible for improving various aspects of intestinal barrier function with the involvement of compositional changes of the microbiota [13]. Additionally, the provision of amylase-pretreated WB as the sole added energy source to human intestinal microbial communities in anaerobic fermentors led to an increase in the abundance of butyrate producers [14].

In addition, soluble fiber-rich barley is expected to reduce the risk of dysbiosis. Barley is rich in $\beta$-glucan, which is easily fermented by Bacteroides and Prevotella [15]. BARLEYmax (Tantangara; BM) is a barley line developed by CSIRO (Commonwealth Scientific and Industrial Research Organisation) in Australia. BM is not a genetically modified crop and it is rich in fructan and resistant starch as well as $\beta$-glucan. A recent report showed that subjects with an intake of $12 \mathrm{~g} /$ day of BM showed significant increases in fecal output and defecation frequency [16]. Compared to the parameters at baseline, an intake of $12 \mathrm{~g} /$ day of BM resulted in a significant increase in the production of SCFAs, an increase in the abundance of Bacteroides and a decrease in the abundance of Clostridium subcluster XIVa [16].

The combination of multiple types of dietary fiber that have different fermentation rates has recently been a topic of interest. It has been reported that rats fed a diet containing resistant starch together with WB had a greater fecal excretion of SCFAs than those fed resistant starch or WB alone, suggesting that the incorporation of WB delayed the site of fermentation of the resistant starch to the distal part of the hindgut [17]. It was concluded that the combination of indigestible carbohydrates may affect both the profile of SCFAs produced by fermentation and the site of SCFA release in the rat hindgut. Concordantly, a human intervention study showed that combining WB with resistant starch had more benefits than supplementation with WB alone [18].

In the present study, we investigated the effects of dietary supplementation with WB and BM individually or in combination in healthy Japanese adult volunteers. We evaluated which dietary fiber source would produce more favorable changes in fecal variables (e.g., higher butyrate, lower phenols, and lower ammonia). We also investigated whether combining WB with BM would modify the fecal microbiota more favorably than supplementation with WB or BM alone.

\section{Materials and Methods}

\subsection{Study Design}

The study was designed as a double-blind controlled randomized trial. Subjects consumed one of four test foods twice a day for 4 weeks as a supplement to their staple foods. The scheme of participant enrollment is shown in Figure 1. The study was performed in conformity with the regulations of the Institutional Review Board of Chiyoda Paramedical Care Clinic (IRB No. 15000088) and the Declaration of Helsinki. All the subjects gave written informed consent before entering the study. The study protocol was registered at the University Hospital Medical Information Network Clinical Trials Registry (UMIN 000027569). 


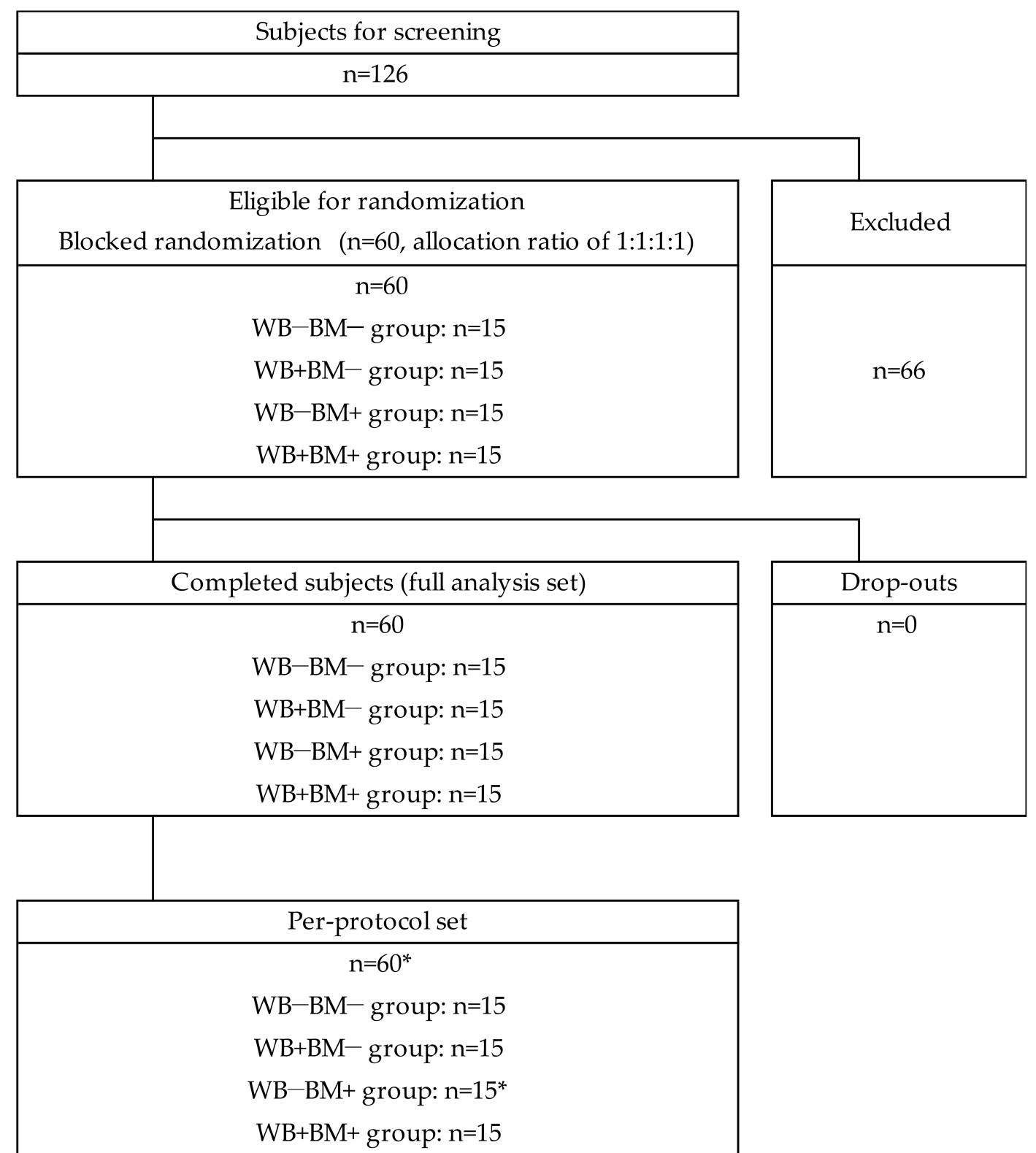

* The data for fecal metabolites from one participant was omitted at statistical analysis.

Figure 1. Scheme of participant enrollment.

\subsection{Subjects}

We enrolled ethnically Japanese subjects who were recruited by CPCC (Creative Pioneer for Clinical Challenge) Co., Ltd. (Tokyo, Japan). The inclusion criteria were as follows: aged 20-64 years, a defecation frequency of less than 5 times/week (i.e., showing a tendency towards constipation) [19], a low intake of fiber (lower than $12 \mathrm{~g} /$ day according to simple dietary records for 4 days comprising 3 weekdays and 1 weekend day), an understanding of the study procedures, and provided written informed consent to participate.

The exclusion criteria were as follows:

1. Regular use of a medicine for intestinal disorders or an aperient (including a laxative).

2. Regular consumption of health foods thought to improve constipation at the time of the screening examination. 
3. Use of any drugs that could affect digestion and nutrient absorption including antibiotics at the time of the screening examination.

4. Inability or unwillingness to stop consuming probiotic or prebiotic supplements such as lactic acid bacteria, Bifidobacterium, Bacillus subtilis var. natto, food fortified with oligosaccharides, dietary fiber, large quantities of sugar or alcohol, barley-rich food, or other dietary health supplements for the entire duration of the study.

5. Having a food allergy.

6. Having a disease urgently needing treatment or having serious complications.

7. Having a history of a digestive organ disease or an operation that could affect digestion, nutrient absorption, or bowel movements.

8. Judged from the answers to the subject background questionnaire to be inappropriate as a subject.

9. Judged from the results of a blood test during the screening examination to be inappropriate as a subject.

10. Currently pregnant or intended to become pregnant during the study period.

11. Currently nursing an infant.

12. Having any drug dependency.

13. Having an anamnesis or medical history of alcohol dependence.

14. Participating in another study involving the intake of food, drugs, or cosmetics, or judged by one of the examining doctors involved in the trial to be inappropriate as a subject, e.g., subjects who plan to change their lifestyle during the test period or who would not obey the rules of the trial.

Sixty subjects participated in this trial, were stratified four blocks according to their sex and age. Fifteen subjects were assigned to each trail group by blocked randomization. (WB-BM-, $\mathrm{WB}-\mathrm{BM}+, \mathrm{WB}+\mathrm{BM}-$, and $\mathrm{WB}+\mathrm{BM}+)$. The subjects ate self-selected foods as accompanying dishes along with the test foods and otherwise maintained the same eating habits before and throughout the trial. Anthropometric measurements (body weight, height, and waist circumference) were performed, and blood samples were collected from a forearm vein and analyzed at baseline and after 4 weeks. Table 1 summarizes the baseline characteristics of the subjects. The four groups were similar with regard to their age, body weight, body mass index, body fat, and blood pressure.

\subsection{Dietary Supplementation}

The four test foods comprised baked cereal bars composed as follows: (1) neither WB nor BM (WB-BM-), (2) WB without BM (WB+BM- diet), (3) BM without WB (WB-BM+ diet), and (4) WB and $\mathrm{BM}(\mathrm{WB}+\mathrm{BM}+$ diet). The subjects ate the cereal bars $(40.7 \mathrm{~g})$ twice daily as a supplement to their staple food. The test foods were manufactured by Ayabe-Yougashi Corp. (Saitama, Japan). First, margarine and brown sugar were mixed together, then egg and vanilla extract were added and all the ingredients were mixed together. Wheat flour, wheat bran, crushed BM (mesh size $2.07 \mathrm{~mm}$ ), and cellulose were added in the proportions shown in Table 1 and mixed. The dough was kept at $4{ }^{\circ} \mathrm{C}$ for $120 \mathrm{~min}$, then sheeted to $15 \mathrm{~mm}$ thickness and cut into $40 \times 75 \mathrm{~mm}$ bar shapes (approximately $46 \mathrm{~g} / \mathrm{bar}$ ). The bars were baked with a tunnel oven at the upper temperature of $146^{\circ} \mathrm{C}$ and lower temperature of $135{ }^{\circ} \mathrm{C}$ for $40 \mathrm{~min}$. Then, the bars were cooled to room temperature and individually pillow-packed with aluminum metallized film. The components of the test foods are listed in Table 2 . Wheat flour was obtained from Nitto Fuji Flour Milling Co., Ltd. (Tokyo, Japan). WB (K-Bran) was obtained from Hoshino Bussan Co. Ltd. (Gunma, Japan), cellulose (Ceolus FD-301) was obtained from Asahi Kasei Corp. (Tokyo, Japan), and BM (BARLEYmax) was obtained from Teijin Limited (Tokyo, Japan). Pearled BM was used for the test foods. The contents of total, soluble, and insoluble dietary fiber in the samples were analyzed using the method of Prosky et al. (AOAC 991.43) [20]. The $\beta$-glucan content in the test foods was measured using the method of McCleary et al. (AOAC 995.16) [21]. The resistant starch content in each sample was analyzed using the method of AOAC 2002.02 [22]. The arabinoxylan content in the test food was calculated from the contents in the WB and 
BM measured using a previously described method [23]. The nutrient components were analyzed by Japan Food Research Laboratories (Tokyo, Japan) and are listed in Table 3. The average weight of the test foods was $40.7 \mathrm{~g}$ and their caloric contents were almost equal. Their total dietary fiber contents were almost equal adjusted by cellulose. We formulated the test foods to taste good by incorporating cocoa powder and brown sugar, and it was difficult to detect a difference in taste among the test foods. As a result, blindness was properly maintained. The features of the test foods are shown in Figure 2. The biggest difference among the test foods was the source of dietary fiber.

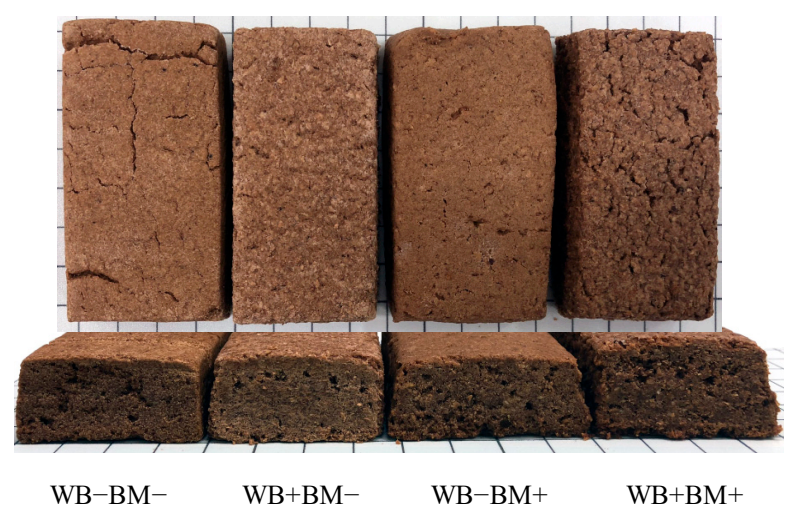

Figure 2. Features of the test foods.

\subsection{Food Frequency Questionnaire}

Daily food intake records were investigated via interviews in which the subjects described their recent meals. A 4-day record of their diet was completed by a registered dietitian at baseline and after 4 weeks. Food records were analyzed using the Standard Tables of Food Composition in Japan 2015, Seventh Revised Version [24] and the software program Excel Eiyokun Version 8 (Kenpakusha, Tokyo, Japan).

Table 1. Baseline characteristics of subjects. ${ }^{a}$

\begin{tabular}{ccccccc}
\hline & & WB-BM-Group & WB+BM-Group & WB-BM+ Group & WB+BM+ Group \\
\hline Subjects & $N$ & 15 & 15 & 15 & 15 \\
Sex (male/female) & $N$ & $5 / 10$ & $5 / 10$ & $5 / 10$ & $4 / 11$ \\
Age b & $\mathrm{Y}$ & $46.4 \pm 8.80$ & $46.4 \pm 7.9$ & $46.5 \pm 8.0$ & $46.4 \pm 10.5$ \\
Height & $\mathrm{Cm}$ & $160.6 \pm 6.6$ & $162.4 \pm 8.6$ & $161.5 \pm 6.6$ & $160.3 \pm 6.3$ \\
Body weight & $\mathrm{Kg}$ & $52.1 \pm 8.8$ & $58.3 \pm 8.5$ & $59.7 \pm 15.1$ & $53.0 \pm 7.1$ \\
Body mass index & $\mathrm{kg} / \mathrm{m}^{2}$ & $20.1 \pm 2.4$ & $22.1 \pm 2.4$ & $22.9 \pm 5.6$ & $20.6 \pm 2.8$ \\
Body fat & $\%$ & $23.1 \pm 6.4$ & $27.5 \pm 5.9$ & $26.0 \pm 9.8$ & $24.9 \pm 9.2$ \\
Systolic blood pressure & $\mathrm{mmHg}$ & $114.7 \pm 10.7$ & $114.1 \pm 11.7$ & $114.5 \pm 12.5$ & $112.7 \pm 11.9$ \\
Diastolic blood pressure & $\mathrm{mmHg}$ & $74.1 \pm 8.0$ & $70.0 \pm 8.2$ & $71.6 \pm 10.4$ & $72.7 \pm 10.1$ \\
Pulse rate & $\mathrm{bpm}$ & $69.2 \pm 10.3$ & $65.2 \pm 8.1$ & $66.5 \pm 8.0$ & $69.7 \pm 8.1$ \\
\hline
\end{tabular}

WB, wheat bran; BM, BARLEYmax. ${ }^{a}$ There were no statistical differences among groups on the basis of the Tukey-Kramer and Steel-Dwass multiple comparison tests. ${ }^{\mathrm{b}}$ Mean \pm standard deviation (SD).

\subsection{Fecal Collection}

Fecal samples were collected at baseline and after 4 weeks from 60 healthy adult volunteers at the Chiyoda Paramedical Care Clinic, Tokyo, Japan, using fecal collection tubes (TechnoSuruga Laboratory Co., Ltd., Shizuoka, Japan). Samples were immediately frozen at $-20{ }^{\circ} \mathrm{C}$, transported on dry ice, and then stored at $-80^{\circ} \mathrm{C}$ until further analysis. 
Table 2. Components of test foods.

\begin{tabular}{ccccc}
\hline & WB- BM- & WB+BM- & WB-BM+ & WB+BM+ \\
\hline Cellulose & $4.5 \mathrm{~g}$ & $1.7 \mathrm{~g}$ & $2.8 \mathrm{~g}$ & - \\
Wheat bran & - & $6.0 \mathrm{~g}$ & - & $6.0 \mathrm{~g}$ \\
BARLEYmax & - & - & $6.0 \mathrm{~g}$ & $6.0 \mathrm{~g}$ \\
Wheat flour & $17.9 \mathrm{~g}$ & $14.9 \mathrm{~g}$ & $13.8 \mathrm{~g}$ & $10.6 \mathrm{~g}$ \\
Egg & $4.4 \mathrm{~g}$ & $4.4 \mathrm{~g}$ & $4.4 \mathrm{~g}$ & $4.4 \mathrm{~g}$ \\
Margarine & $9.2 \mathrm{~g}$ & $9.2 \mathrm{~g}$ & $9.2 \mathrm{~g}$ & $9.2 \mathrm{~g}$ \\
Emulsifier & $0.5 \mathrm{~g}$ & $0.5 \mathrm{~g}$ & $0.5 \mathrm{~g}$ & $0.5 \mathrm{~g}$ \\
Brown sugar & $7.3 \mathrm{~g}$ & $7.3 \mathrm{~g}$ & $7.3 \mathrm{~g}$ & $7.3 \mathrm{~g}$ \\
Cocoa powder & $0.9 \mathrm{~g}$ & $0.9 \mathrm{~g}$ & $0.9 \mathrm{~g}$ & $0.9 \mathrm{~g}$ \\
Salt & $0.05 \mathrm{~g}$ & $0.05 \mathrm{~g}$ & $0.05 \mathrm{~g}$ & $0.05 \mathrm{~g}$ \\
Vanilla flavor & $1.2 \mathrm{~g}$ & $1.2 \mathrm{~g}$ & $1.2 \mathrm{~g}$ & $1.2 \mathrm{~g}$ \\
Caramel color & $0.2 \mathrm{~g}$ & - & - & - \\
Total & $46.15 \mathrm{~g}$ & $46.15 \mathrm{~g}$ & $46.15 \mathrm{~g}$ & $46.15 \mathrm{~g}$ \\
\hline
\end{tabular}

Table 3. Nutritional profiles of test foods. ${ }^{a}$

\begin{tabular}{ccccc}
\hline & WB-BM- & WB+BM- & WB-BM+ & WB+BM+ \\
\hline Energy $(\mathrm{kcal} / 100 \mathrm{~g})$ & 454 & 447 & 455 & 448 \\
Protein $(\mathrm{g} / 100 \mathrm{~g})$ & 6.0 & 7.8 & 7.1 & 8.6 \\
Fat $(\mathrm{g} / 100 \mathrm{~g})$ & 22.1 & 22.6 & 22.2 & 23.4 \\
Available carbohydrate $(\mathrm{g} / 100 \mathrm{~g})$ & 50.9 & 46 & 49.6 & 43.5 \\
Total dietary fiber $(\mathrm{g} / 100 \mathrm{~g})$ & 12.7 & 13.0 & 12.0 & 12.1 \\
Soluble dietary fiber $(\mathrm{g} / 100 \mathrm{~g})$ & $<0.5$ & 1.1 & 1.2 & 1.8 \\
Insoluble dietary fiber $(\mathrm{g} / 100 \mathrm{~g})$ & 12.0 & 11.5 & 10.5 & 10.7 \\
ß-glucan $(\mathrm{g} / 100 \mathrm{~g})$ & nd. & 0.4 & 0.8 & 1.2 \\
Arabinoxylan $(\mathrm{g} / 100 \mathrm{~g})$ & bd. & 2.6 & 1.0 & 3.6 \\
Resistant starch $(\mathrm{g} / 100 \mathrm{~g})$ & nd. & nd. & 1.4 & 1.1 \\
\hline
\end{tabular}

a Weight of test food: $40.7 \mathrm{~g}$ after baking process. ${ }^{\mathrm{b}}$ Calculated value from analytical data of arabinoxylan in wheat bran and BARLEYmax.

\subsection{Anthropometrical Measures and Biochemical Analysis}

Body mass index using an InBody570 body composition analyzer (InBody Japan, Inc., Tokyo, Japan). Physical examination (body weight, body mass index, body fat) were conducted using an InBody570 body composition analyzer (InBody Japan, Inc., Tokyo, Japan).

Vital signs (systolic blood pressure, diastolic blood pressure, pulse rate) were measured by fully automatic blood pressure monitor TM2656VPW (A\&D Company, Ltd., Tokyo, Japan).

Blood samples and urine samples were obtained after overnight fast for clinical examinations performed by a commercial laboratory (LSI Medience Corporation, Tokyo, Japan). In particular, serum proteins (total protein (TP), albumin (ALB)), serum enzymes (aspartate aminotransferase (AST), alanine transaminase (ALT), lactate dehydrogenase (LDH), alkaline phosphatase (ALP), gamma-glutamyl transpeptidase ( $\gamma$-GTP), creatine phosphokinase (CPK)), serum lipid (total cholesterol (T-Cho), HDL cholesterol (HDL-Cho), LDL cholesterol (LDL-Cho), triglyceride(TG)), serum total bilirubin (T-BIL), serum urea nitrogen (BUN), serum creatinine (CRE), serum uric acid (UA), serum electrolyte $(\mathrm{Na}, \mathrm{Cl}, \mathrm{K}, \mathrm{Ca})$, blood fasting glucose (GLC) and glycosylated albumin ( $\mathrm{HbA} 1 \mathrm{c})$, hematological examinations (white blood cell (WBC), red blood cell (RBC), hemoglobin $(\mathrm{Hb})$, hematocrit (Ht), platelet (PLT)), and urinary qualitative tests were conducted. These markers were analyzed to examine the safety of the test foods. Specifically, serum protein, T-BIL, and the several enzymes measured are markers of liver function, serum lipids are markers of lipid metabolism, serum BUN, CRE, UA, and electrolytes are markers of kidney function, and blood GLC and $\mathrm{HbA1c}$ are markers of glucose metabolism. Hematological examinations (WBC, RBC, Hb, Ht, PLT) are markers of inflammation, anemia, and coagulation abnormality. 


\subsection{DNA Extraction and Analysis of Intestinal Microbiota Composition by High-Throughput Sequencing}

Each fecal sample (about $100 \mathrm{mg}$ ) was suspended in GTC buffer (Tris- $\mathrm{HCl}$ ( $\mathrm{pH}$ 9.0), Tris-ethylenediaminetetraacetic acid ( $\mathrm{pH}$ 8.0), guanidine thiocyanate, and bromothymol blue). After centrifugation, DNA was extracted from the suspension using an automatic nucleic acid extractor (Precision System Science, Chiba, Japan). MagDEA DNA 200 (GC) (Precision System Science) was used as the reagent for automatic nucleic acid extraction [25].

The V3-V4 region of the bacterial 16S rRNA gene was amplified from the DNA samples using the 341f [26] and R806 [27] primers. The forward and reverse primers both contained an 8-bp indexing sequence to allow for multiplexing [25]. The V3-V4 regions of the bacterial 16S rRNA fragments were amplified and the PCR (polymerase chain reaction) products were purified through a MultiScreen ${ }^{\mathrm{TM}}$ PCRu96 filter plate (Merck Millipore, Burlington, MA, USA). To prepare the amplicon pool, the purified PCR products were quantified by real-time quantitative PCR (q-PCR) on a Rotor-Gene ${ }^{\circledR} \mathrm{Q}$ quantitative thermal cycler using MightyAmp ${ }^{\circledR}$ real-time PCR buffer containing SYBR ${ }^{\circledR}$ Plus (TaKaRa Bio, Inc., Shiga, Japan) [25]. The pooled PCR products were sequenced using the MiSeq ${ }^{\circledR}$ reagent kit v.3 (Illumina, San Diego, CA, USA) via paired-end $2 \times 284$-bp cycles on the MiSeq ${ }^{\circledR}$ system ( 600 cycles). The paired-end reads were concatenated using fastq-join with the default options [28]. Only joined reads that had a quality value score of $\geq 20$ for more than $99 \%$ of the sequence were extracted using the fastq_quality_filter and fastq_quality_trimmer algorithms of the FASTX-Toolkit [29]. The chimeric sequences were deleted with usearch6.1 by using split-libraries-fastq.py in QIIME ver 1.8.0 (the University of Colorado, Colorado, USA) [30].

Bacterial identification from chimeric-filtered sequences was performed using the Ribosomal Database Project version 2.11 (Michigan State University, Michigan, USA) [31,32] and QIIME ver 1.8.0 pipeline [30]. The bacterial taxonomy identified was visualized using the Metagenome@KIN version 2.2.1 analysis software (cut off phylum > 0.8) (World Fusion, Tokyo, Japan). In QIIME, the sequences were clustered into operational taxonomic units (OTUs) on the basis of having $>97 \%$ similarity with sequences in the Greengenes database [33] using pick_open_reference_otus.py in QIIME. The OTUs were tabulated on the taxonomic levels from phylum to genus and their relative abundances were calculated using plot_taxa_summary.py in QIIME. Plots showing the alpha diversity from open-reference picked OTU tables were constructed from the diversity metrics of phylogenetic diversity whole tree, chao1 index, observed OTU number (observed species), and Shannon index using alpha_diversity.py in QIIME. Beta diversity was calculated from the unweighted and weighted unifrac distance matrixes in beta_diversity.py in QIIME. All the above procedures were performed by TechnoSuruga Laboratory, Co., Ltd.

\subsection{Fecal Organic Acids, Indoles, Phenols, and Ammonia}

For the determination of organic acids, feces were suspended in distilled water, heated at $85{ }^{\circ} \mathrm{C}$ for $15 \mathrm{~min}$ to inactivate viruses, and then centrifuged according to the previous report [34]. It was confirmed that SCFAs are stable in feces at $85^{\circ} \mathrm{C}$ by a previous study, in which the recovery rate of all SCFAs heated at that temperature was more than $96 \%$. The concentrations of organic acids such as formic acid, acetic acid, propionic acid, isobutyrate, butyric acid, valeric acid, isovaleric acid, lactic acid, and succinic acid in feces were measured using a high-performance liquid chromatography organic acid analysis system with a Prominence CDD-10A conductivity detector (Shimadzu, Kyoto, Japan); two tandemly-arranged Shim-pack SCR-102(H) columns (300 $\mathrm{mm} \times 8 \mathrm{~mm}$ inner diameter (ID)); a Shim-pack SCR-102(H) guard column (50 mm $\times 6 \mathrm{~mm}$ ID) [35]. The HPLC calibration curve for the measurement for the organic acids was done with prepared standards solutions.

For the measurement of indoles and phenols, feces were suspended with phosphate buffer including 4-isopropylphenol as an internal standard. Each sample was heated and extracted with acetonitrile and centrifuged. The supernatant was dehydrated and purified using a sodium sulfate drying cartridge (Bond Elut LRC, Agilent Technologies, Santa Clara, CA, USA) with a C18 cartridge (Smart SPE C18-30, AiSTI SCIENCE, Wakayama, Japan) and a PSA (primary-secondary amine) 
cartridge (Smart SPE PSA-30, AiSTI SCIENCE, Japan), and placed into a vial. Indoles and phenols in feces were measured using gas chromatography with mass spectrometry (QP-2010, Shimadzu) and a capillary column (inert cap WAX, $30 \mathrm{~m} \times 0.25 \mathrm{~mm} \times 0.25 \mu \mathrm{m}$, GL Sciences, Tokyo, Japan). The GC/MS (gas chromatography - mass spectrometry)calibration curve for the measurement for the indoles and phenols was done with prepared standard solutions.

For the measurement of the ammonium ion concentration, feces were suspended, filtered, and diluted in distilled water. The ammonium ion concentration in feces was measured using an ion chromatography system (ICS-1000, Dionex, Sunnyvale, CA, USA) with an IonPac ${ }^{\mathrm{TM}}$ CS12A column $\left(4 \mathrm{~mm} \times 250 \mathrm{~mm}\right.$, Dionex) and an IonPac ${ }^{\mathrm{TM}}$ CG12A guard column $(4 \mathrm{~mm} \times 50 \mathrm{~mm}$, Dionex).

All the above procedures were performed by TechnoSuruga Laboratory, Co., Ltd.

\subsection{Statistical Analysis}

Sample sizes were calculated from previous studies [16,36]. Fifteen subjects were required per group (type I error $(\alpha)=0.05,1-\beta=0.80$ ). Data normality was checked using a quantile-quantile plot. Bartlett's test was used to test for the homogeneity of variances. Data were analyzed using SPSS Statistics version 20 (IBM Corporation, Armonk, NY, USA). Two-way analysis of variance was applied for the primary (microbiota abundance) and secondary (fecal variables) outcomes. The Tukey-Kramer and Steel-Dwass multiple comparison tests were used to compare the values of all outcomes and nutritional intakes. A correlation analysis between fecal metabolites and bacterial abundance was performed using Spearman's rank sum test. In all analyses, a two-sided $p$-value $<0.05$ was considered significant.

\section{Results}

\subsection{Dietary Intake and Adherence}

All the subjects completed the trial. No adverse events corresponding to the intake of the test food, such as gastrointestinal problems, were observed during the trial. Statistical analyses were performed for the subjects in each group ( $n=15$ per group) in the per-protocol set analysis.

Daily energy and nutrient intakes are summarized in Table 4 . There were no significant differences among the calorie or nutrient intakes of the four groups during 4 weeks. The main dietary fiber sources of the subjects were vegetables, pulses, cereals, and potatoes. No noticeable difference in dietary fiber source among the groups was observed.

\subsection{Anthropometrical Measures and Biochemical Analysis}

The effects of WB and BM intakes on body weight, body mass index, body fat, and blood pressure at baseline and week 4 are shown in supplementary Table S1. No significant differences were detected among groups at baseline and week 4 . The serum biochemistry results of the patients at baseline and week 4 are shown in supplementary Tables S2 and S3. At baseline, the mean serum concentration of albumin (ALB) in the WB+BM- group was significantly lower than that in the other three groups. However, this difference was quite small $(0.2 \mathrm{~g} / \mathrm{dL})$. All the patients were included for this analysis. No other significant differences were detected among groups at baseline.

Slight but significant changes in alanine aminotransferase (ALT), lactate dehydrogenase (LDH), creatinine (CRE), and $\mathrm{HbA1c}$ (NGSP) were observed at week 4 as compared to baseline. These changes were random, were not observed in the specific test group, and were considered to be within the normal range of physiological variation. Urinary markers were normal. Therefore, it was considered that the intake of WB and BM individually or in combination had no harmful effects on the health of all subjects.

\subsection{Fecal Microbiota Composition}

The relative abundances of bacterial phyla in the fecal samples of participants at baseline and week 4 are shown in Table 5 and Figures 3 and 4 . A significant interactive effect of WB and BM on the 
abundance of Bacteroidetes were observed at week 4, whereas no significant differences among groups were observed at baseline. There were no significant differences in the abundances of other bacterial phyla. Changes in the relative abundances of bacterial phyla in the fecal samples of participants between baseline and week 4 are shown in Table S4. There were no significant differences in the abundances of other bacterial phyla. Significant changes in the relative abundances of bacterial phyla between baseline and week 4 were not observed.

The relative abundances of selected bacterial genera in the fecal samples of participants at baseline and week 4 are shown in Table 6. A significant interactive effect of WB and BM on the abundance of Bacteroides was observed at week 4, whereas no significant differences were observed at baseline. The abundances of most butyrate-producing genera including Ruminococcus, Faecalibacterium, Coprococcus, Roseburia, and Ruminiclostridium, but excluding Anaerostipes, at week 4 were significantly higher in the $\mathrm{WB}$ groups $(\mathrm{WB}+\mathrm{BM}-$ and $\mathrm{WB}+\mathrm{BM}+)$ than in the non-WB groups (WB-BM- and $\mathrm{WB}-\mathrm{BM}+$ ), whereas no significant differences were observed at baseline. The abundances of most butyrate-producing genera at baseline were significantly lower in the BM groups (WB-BM+ and $\mathrm{WB}+\mathrm{BM}+$ ) than in the non-BM groups ( $\mathrm{WB}-\mathrm{BM}-$ and $\mathrm{WB}+\mathrm{BM}-$ ), whereas significant differences were not observed at week 4. By contrast, the abundance of Anaerostipes was significantly lower in the $\mathrm{WB}$ groups $(\mathrm{WB}+\mathrm{BM}-$ and $\mathrm{WB}+\mathrm{BM}+$ ) than in the non-WB groups ( $\mathrm{WB}-\mathrm{BM}-$ and $\mathrm{WB}-\mathrm{BM}+$ ). There were no significant differences in other bacteria genera. Changes in the relative abundances of bacterial genera in the fecal samples of participants between baseline and week 4 are shown in Table S5. A significant interactive effect of WB and BM on the abundance of genus Anaerostipes was observed. By contrast, changes in the abundance of Clostridium were significantly more pronounced in the $\mathrm{BM}$ groups $(\mathrm{WB}-\mathrm{BM}+$ and $\mathrm{WB}+\mathrm{BM}+)$ than in the non- $\mathrm{BM}$ groups $(\mathrm{WB}-\mathrm{BM}-$ and $\mathrm{WB}+\mathrm{BM}-$ ). The same tendency was observed for the abundances of most butyrate-producing genera $(p=0.060)$. There were no significant changes between baseline and week 4 in other bacteria genera.

Table 4. Energy and nutrition intakes of subjects during the test period. ${ }^{\text {a }}$

\begin{tabular}{|c|c|c|c|}
\hline & Group & Average Daily Record & $p$-Value ${ }^{b}$ \\
\hline $\begin{array}{c}\text { Energy } \\
\text { (kcal) }\end{array}$ & $\begin{array}{l}\mathrm{WB}-\mathrm{BM}- \\
\mathrm{WB}+\mathrm{BM}- \\
\mathrm{WB}-\mathrm{BM}+ \\
\mathrm{WB}+\mathrm{BM}+\end{array}$ & $\begin{array}{l}1403.0 \pm 374.2 \\
1491.3 \pm 446.8 \\
1361.8 \pm 320.2 \\
1364.2 \pm 361.9\end{array}$ & 0.207 \\
\hline $\begin{array}{l}\text { Protein } \\
\quad(g)\end{array}$ & $\begin{array}{l}\mathrm{WB}-\mathrm{BM}- \\
\mathrm{WB}+\mathrm{BM}- \\
\mathrm{WB}-\mathrm{BM}+ \\
\mathrm{WB}+\mathrm{BM}+\end{array}$ & $\begin{array}{l}51.7 \pm 16.8 \\
54.3 \pm 18.2 \\
51.5 \pm 13.5 \\
48.9 \pm 15.2\end{array}$ & 0.343 \\
\hline $\begin{array}{l}\text { Fat } \\
(\mathrm{g})\end{array}$ & $\begin{array}{l}\mathrm{WB}-\mathrm{BM}- \\
\mathrm{WB}+\mathrm{BM}- \\
\mathrm{WB}-\mathrm{BM}+ \\
\mathrm{WB}+\mathrm{BM}+\end{array}$ & $\begin{array}{l}51.6 \pm 20.7 \\
55.0 \pm 26.5 \\
47.6 \pm 15.4 \\
49.8 \pm 20.0\end{array}$ & 0.261 \\
\hline $\begin{array}{c}\text { Carbohydrate } \\
\text { (g) }\end{array}$ & $\begin{array}{l}\mathrm{WB}-\mathrm{BM}- \\
\mathrm{WB}+\mathrm{BM}- \\
\mathrm{WB}-\mathrm{BM}+ \\
\mathrm{WB}+\mathrm{BM}+\end{array}$ & $\begin{array}{l}174.5 \pm 54.9 \\
185.7 \pm 57.6 \\
174.4 \pm 50.9 \\
175.4 \pm 53.6\end{array}$ & 0.604 \\
\hline $\begin{array}{l}\text { Total dietary fiber } \\
\qquad(\mathrm{g})\end{array}$ & $\begin{array}{l}\mathrm{WB}-\mathrm{BM}- \\
\mathrm{WB}+\mathrm{BM}- \\
\mathrm{WB}-\mathrm{BM}+ \\
\mathrm{WB}+\mathrm{BM}+\end{array}$ & $\begin{array}{l}8.8 \pm 3.4 \\
8.3 \pm 3.3 \\
8.6 \pm 3.4 \\
8.6 \pm 3.6\end{array}$ & 0.904 \\
\hline
\end{tabular}

a Average daily records for 4 days. All values are mean $\pm \mathrm{SD}, n=15$ in all groups. ${ }^{\mathrm{b}}$ One-way ANOVA. 
Comparisons of the diversity of the fecal microbiota between the samples obtained at baseline and those obtained at week 4 are shown in Table 7 . No significant differences were observed in any diversity indexes.

\subsection{Fecal Organic Acids and Putrefaction Products}

The data for fecal organic acids and putrefaction products from one individual in the $\mathrm{WB}-\mathrm{BM}+$ group was excluded based on outlier detection using the Smirnov-Grubbs test. This anomalous result might have been caused by an error in the fecal sampling procedure. The fecal SCFAs and organic acid concentrations of subjects at baseline and week 4 are shown in Table 8 . The concentrations of acetate, $n$-butyrate, and total SCFAs were significantly higher in the WB groups (WB+BM- and WB+BM+) than in the non-WB groups ( $\mathrm{WB}-\mathrm{BM}-$ and $\mathrm{WB}-\mathrm{BM}+)$. Changes in the fecal concentrations of SCFAs and organic acids of subjects between baseline and week 4 are shown in supplementary Table S6. Changes in the concentrations of acetate and total SCFAs were significantly higher in the WB groups (WB+BMand $\mathrm{WB}+\mathrm{BM}+$ ) than in the non-WB groups ( $\mathrm{WB}-\mathrm{BM}-$ and $\mathrm{WB}-\mathrm{BM}+)$. The same tendencies were observed in the concentrations of propionate and $n$-butyrate ( $p=0.0762$ and 0.0566 , respectively). There were no significant changes between baseline and week 4 in the concentrations of other SCFAs.

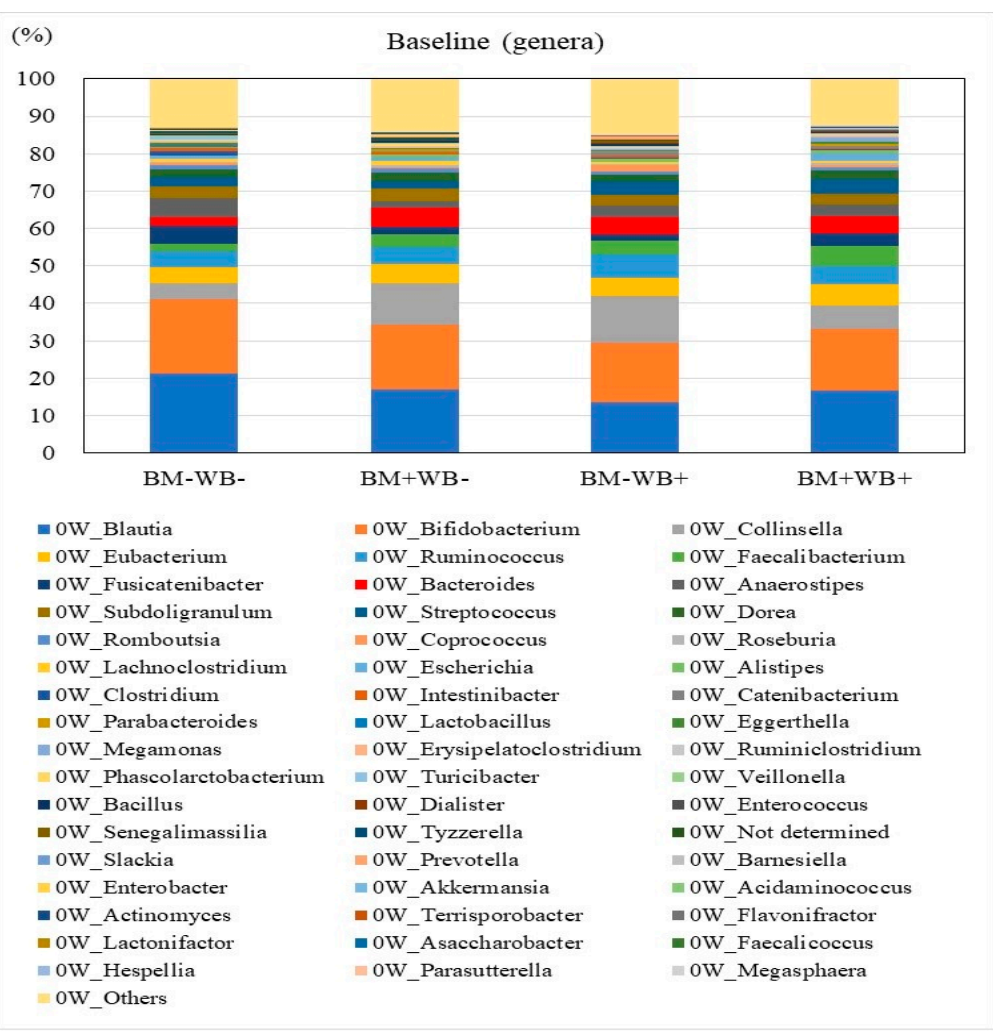

Figure 3. The average relative abundances of detected bacteria genera in stool samples obtained at baseline. No significant differences were observed among the test groups at baseline. 


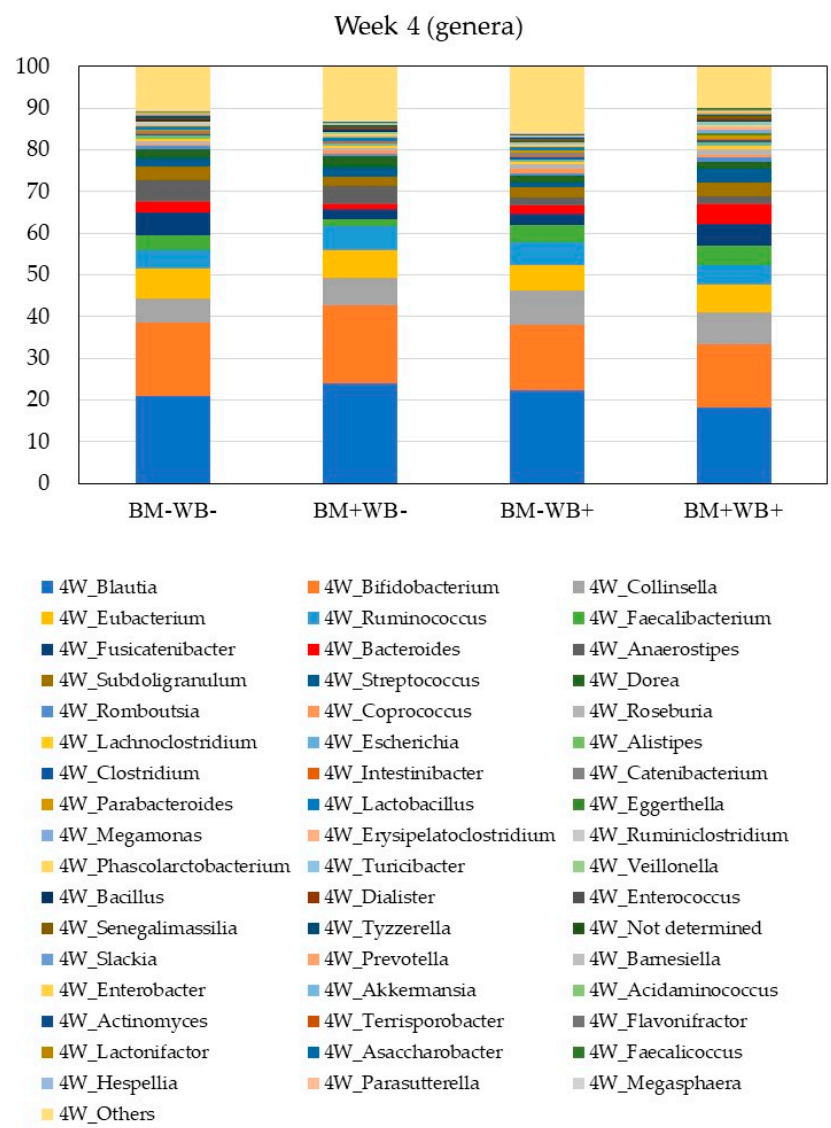

Figure 4. The average relative abundances of detected bacteria genera in stool samples obtained at week 4. A significant interactive effect of $\mathrm{WB}$ and $\mathrm{BM}$ on the abundances of Bacteroides was observed $(p<0.05)$. The abundances of Anaerostipes was significantly lower in the WB+groups than in the WBgroups at week $4(p<0.05)$.

The concentrations of fecal putrefaction products in the samples obtained at baseline and week 4 are shown in Table 9. The concentrations of $p$-cresol and total putrefaction products except ammonia were significantly lower in the $\mathrm{WB}$ groups $(\mathrm{WB}+\mathrm{BM}-$ and $\mathrm{WB}+\mathrm{BM}+)$ than in the non-WB groups $(\mathrm{WB}-\mathrm{BM}-$ and $\mathrm{WB}-\mathrm{BM}+)$. Changes in the concentrations of fecal putrefaction products between baseline and week 4 are shown in Table S7. There were no significant changes between baseline and week 4 in the concentrations of putrefaction products.

A positive Spearman's rank moment correlation coefficient was observed between the concentration of $n$-butyrate and the abundance of butyrate-producing bacteria $(p=0.012)$. The relationship between the abundance of butyrate producers and the fecal $n$-butyrate concentration is shown in Figure 5. 
Table 5. Relative abundances of bacteria phyla in fecal samples obtained at baseline and week 4 . $^{\text {a }}$

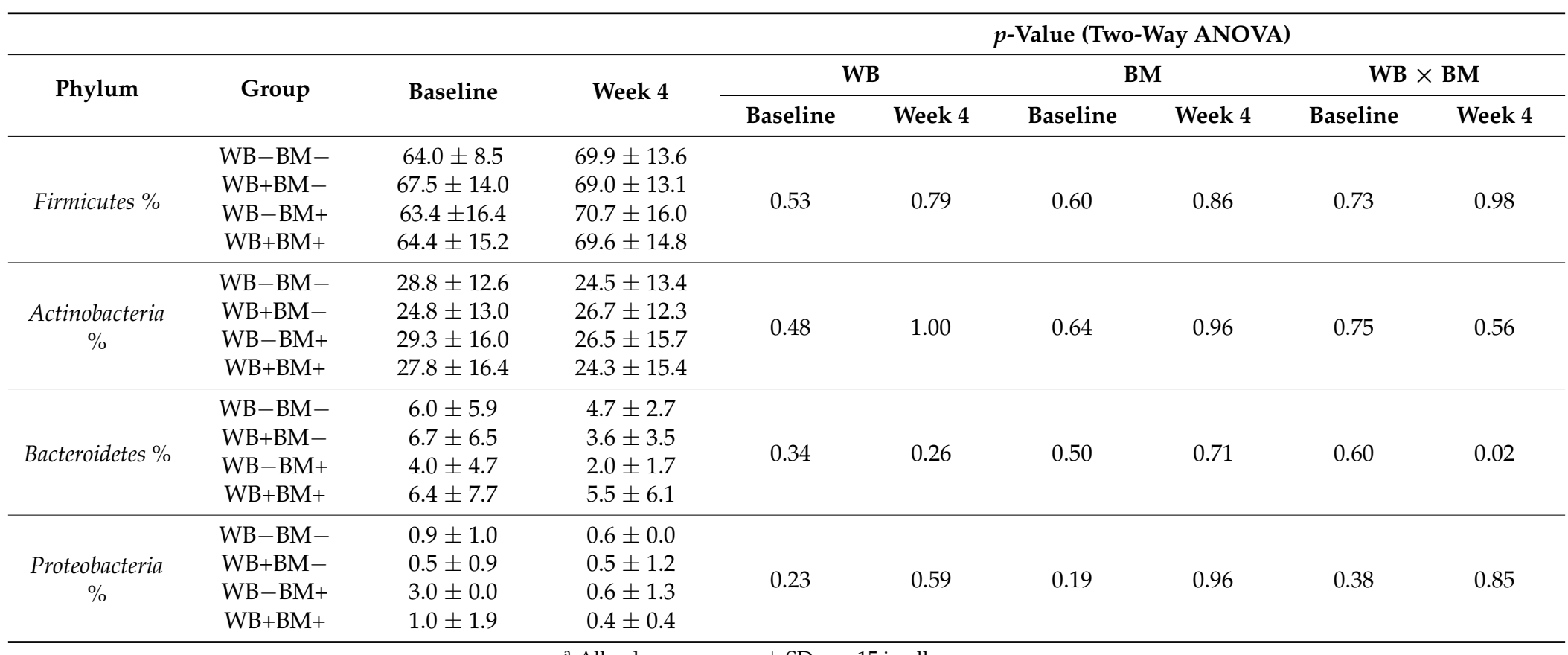

${ }^{a}$ All values are mean $\pm \mathrm{SD}, n=15$ in all groups. 
Table 6. Relative abundances of selected bacteria genera in fecal samples obtained at baseline and week 4 . $^{\text {a }}$

\begin{tabular}{|c|c|c|c|c|c|c|c|c|c|}
\hline \multirow{3}{*}{ Genus } & \multirow{3}{*}{ Group } & \multirow{3}{*}{ Baseline } & \multirow{3}{*}{ Week 4} & \multicolumn{6}{|c|}{$p$-Value (Two-Way ANOVA) } \\
\hline & & & & \multicolumn{2}{|c|}{ WB } & \multicolumn{2}{|c|}{$\mathbf{B M}$} & \multicolumn{2}{|c|}{$\mathbf{W B} \times \mathbf{B M}$} \\
\hline & & & & Baseline & Week 4 & Baseline & Week 4 & Baseline & Week 4 \\
\hline \multirow{4}{*}{ Bacteroides \% } & $\mathrm{WB}-\mathrm{BM}-$ & $4.2 \pm 4.8$ & $3.1 \pm 1.8$ & \multirow{4}{*}{0.34} & \multirow{4}{*}{0.31} & \multirow{4}{*}{0.46} & \multirow{4}{*}{0.87} & \multirow{4}{*}{0.70} & \multirow{4}{*}{0.03} \\
\hline & $\mathrm{WB}+\mathrm{BM}-$ & $4.9 \pm 5.7$ & $2.2 \pm 2.2$ & & & & & & \\
\hline & $\mathrm{WB}-\mathrm{BM}+$ & $2.7 \pm 3.9$ & $1.4 \pm 1.3$ & & & & & & \\
\hline & $\mathrm{WB}+\mathrm{BM}+$ & $4.5 \pm 5.8$ & $3.7 \pm 4.5$ & & & & & & \\
\hline \multirow{4}{*}{$\begin{array}{c}\text { Bifidobacterium } \\
\%\end{array}$} & $\mathrm{WB}-\mathrm{BM}-$ & $19.5 \pm 10.3$ & $17.2 \pm 12.7$ & \multirow{4}{*}{0.23} & \multirow{4}{*}{0.77} & \multirow{4}{*}{0.52} & \multirow{4}{*}{0.97} & \multirow{4}{*}{0.50} & \multirow{4}{*}{0.82} \\
\hline & $\mathrm{WB}+\mathrm{BM}-$ & $13.6 \pm 10.8$ & $17.0 \pm 13.4$ & & & & & & \\
\hline & $\mathrm{WB}-\mathrm{BM}+$ & $19.4 \pm 13.1$ & $18.0 \pm 10.7$ & & & & & & \\
\hline & $\mathrm{WB}+\mathrm{BM}+$ & $17.7 \pm 13.5$ & $16.4 \pm 12.5$ & & & & & & \\
\hline \multirow{4}{*}{ Lactobacillus \% } & $\mathrm{WB}-\mathrm{BM}-$ & $0.2 \pm 0.4$ & $0.4 \pm 1.0$ & \multirow{4}{*}{0.55} & \multirow{4}{*}{0.96} & \multirow{4}{*}{0.74} & \multirow{4}{*}{0.33} & \multirow{4}{*}{0.41} & \multirow{4}{*}{0.44} \\
\hline & $\mathrm{WB}+\mathrm{BM}-$ & $0.2 \pm 0.6$ & $0.7 \pm 2.4$ & & & & & & \\
\hline & $\mathrm{WB}-\mathrm{BM}+$ & $0.4 \pm 0.9$ & $0.4 \pm 0.7$ & & & & & & \\
\hline & $\mathrm{WB}+\mathrm{BM}+$ & $0.1 \pm 0.4$ & $0.1 \pm 0.2$ & & & & & & \\
\hline & $\mathrm{WB}-\mathrm{BM}-$ & $0.1 \pm 0.2$ & $0.2 \pm 0.4$ & & & & & & \\
\hline & $\mathrm{WB}+\mathrm{BM}-$ & $0.1 \pm 0.2$ & $0.1 \pm 0.2$ & & & & & & \\
\hline Prevotella \% & $\mathrm{WB}-\mathrm{BM}+$ & $0.4 \pm 1.5$ & $0.1 \pm 0.3$ & 0.45 & 0.38 & 0.47 & 0.42 & 0.58 & 0.20 \\
\hline & $\mathrm{WB}+\mathrm{BM}+$ & $0.1 \pm 0.3$ & $0.4 \pm 0.9$ & & & & & & \\
\hline & $\mathrm{WB}-\mathrm{BM}-$ & $6.8 \pm 4.5$ & $4.9 \pm 3.4$ & & & & & & \\
\hline & $\mathrm{WB}+\mathrm{BM}-$ & $4.4 \pm 3.3$ & $3.6 \pm 2.9$ & & & & & & \\
\hline Clostridium \% & $\mathrm{WB}-\mathrm{BM}+$ & $4.2 \pm 3.8$ & $5.0 \pm 4.1$ & 0.66 & 0.67 & 0.55 & 0.35 & 0.06 & 0.36 \\
\hline & $\mathrm{WB}+\mathrm{BM}+$ & $5.7 \pm 4.6$ & $5.5 \pm 5.0$ & & & & & & \\
\hline & $\mathrm{WB}-\mathrm{BM}-$ & $3.5 \pm 2.5$ & $5.2 \pm 5.3$ & & & & & & \\
\hline Anaprostines $\%$ & $\mathrm{WB}+\mathrm{BM}-$ & $2.0 \pm 2.3$ & $2.2 \pm 2.2$ & 097 & $-\Omega 01$ & 020 & 071 & 014 & 069 \\
\hline Anaerostıpes \% & $\mathrm{WB}-\mathrm{BM}+$ & $3.1 \pm 3.6$ & $4.5 \pm 4.3$ & 0.97 & $<0.01$ & 0.29 & 0.71 & 0.14 & 0.69 \\
\hline & WB+BM+ & $4.7 \pm 6.2$ & $2.2 \pm 1.8$ & & & & & & \\
\hline & $\mathrm{WB}-\mathrm{BM}-$ & $12.7 \pm 7.4$ & $8.7 \pm 4.4$ & & & & & & \\
\hline Butyrate & $\mathrm{WB}+\mathrm{BM}-$ & $11.1 \pm 6.4$ & $12.0 \pm 7.1$ & & & & & & \\
\hline producers $\mathrm{b} \%$ & $\mathrm{WB}-\mathrm{BM}+$ & $6.9 \pm 6.5$ & $8.6 \pm 4.5$ & 0.77 & 0.05 & 0.03 & 0.76 & 0.22 & 0.80 \\
\hline & $\mathrm{WB}+\mathrm{BM}+$ & $9.5 \pm 5.7$ & $11.2 \pm 5.4$ & & & & & & \\
\hline
\end{tabular}

${ }^{a}$ All values are mean \pm SD, $n=15$ in all groups. ${ }^{b}$ Sum of Ruminococcus, Faecalibacterium, Coprococcus, Roseburia, and Ruminiclostridium. 
Table 7. Comparison of gut microbiota diversity between fecal samples obtained at baseline and at week $4 .{ }^{\text {a }}$

\begin{tabular}{|c|c|c|c|c|c|c|c|c|c|}
\hline \multirow{3}{*}{ Diversity Index } & \multirow{3}{*}{ Group } & \multirow{3}{*}{ Baseline } & \multirow{3}{*}{ Week 4} & \multicolumn{6}{|c|}{$p$-Value (Two-Way ANOVA) } \\
\hline & & & & \multicolumn{2}{|c|}{ WB } & \multicolumn{2}{|c|}{$\mathbf{B M}$} & \multicolumn{2}{|c|}{$\mathbf{W B} \times \mathbf{B M}$} \\
\hline & & & & Baseline & Week 4 & Baseline & Week 4 & Baseline & Week 4 \\
\hline \multirow{4}{*}{$\begin{array}{c}\text { Phylogenetic } \\
\text { diversity } \\
\text { (PD_whole_tree) }\end{array}$} & $\mathrm{WB}-\mathrm{BM}-$ & $27.9 \pm 4.3$ & $27.1 \pm 6.3$ & \multirow{4}{*}{0.38} & \multirow{4}{*}{0.93} & \multirow{4}{*}{0.54} & \multirow{4}{*}{0.91} & \multirow{4}{*}{0.70} & \multirow{4}{*}{0.81} \\
\hline & $\mathrm{WB}+\mathrm{BM}-$ & $28.9 \pm 10.0$ & $27.4 \pm 7.5$ & & & & & & \\
\hline & $\mathrm{WB}-\mathrm{BM}+$ & $25.9 \pm 8.5$ & $27.4 \pm 7.8$ & & & & & & \\
\hline & $\mathrm{WB}+\mathrm{BM}+$ & $28.5 \pm 6.5$ & $26.8 \pm 6.0$ & & & & & & \\
\hline \multirow{4}{*}{ Chao1 } & $\mathrm{WB}-\mathrm{BM}-$ & $1123.3 \pm 184.5$ & $1144.4 \pm 294.7$ & \multirow{4}{*}{0.24} & \multirow{4}{*}{0.90} & \multirow{4}{*}{0.34} & \multirow{4}{*}{0.62} & \multirow{4}{*}{0.96} & \multirow{4}{*}{0.89} \\
\hline & $\mathrm{WB}+\mathrm{BM}-$ & $1230.4 \pm 451.4$ & $1166.4 \pm 322.4$ & & & & & & \\
\hline & $\mathrm{WB}-\mathrm{BM}+$ & $1044.8 \pm 348.8$ & $1115.6 \pm 332.7$ & & & & & & \\
\hline & $\mathrm{WB}+\mathrm{BM}+$ & $1142.9 \pm 286.3$ & $1114.1 \pm 300.9$ & & & & & & \\
\hline \multirow{4}{*}{$\begin{array}{l}\text { Observed number } \\
\text { of OTUs } \\
\text { (observed_species) }\end{array}$} & $\mathrm{WB}-\mathrm{BM}-$ & $630.4 \pm 101.6$ & $626.5 \pm 149.6$ & \multirow{4}{*}{0.20} & \multirow{4}{*}{0.74} & \multirow{4}{*}{0.35} & \multirow{4}{*}{0.89} & \multirow{4}{*}{0.98} & \multirow{4}{*}{0.73} \\
\hline & $\mathrm{WB}+\mathrm{BM}-$ & $688.7 \pm 251.4$ & $655.0 \pm 165.4$ & & & & & & \\
\hline & $\mathrm{WB}-\mathrm{BM}+$ & $585.8 \pm 180.7$ & $635.4 \pm 175.8$ & & & & & & \\
\hline & $\mathrm{WB}+\mathrm{BM}+$ & $646.4 \pm 150.8$ & $634.8 \pm 167.5$ & & & & & & \\
\hline \multirow{4}{*}{ Shannon index } & $\mathrm{WB}-\mathrm{BM}-$ & $5.5 \pm 0.5$ & $5.6 \pm 0.5$ & \multirow{4}{*}{0.15} & \multirow{4}{*}{0.70} & \multirow{4}{*}{0.39} & \multirow{4}{*}{0.79} & \multirow{4}{*}{0.45} & \\
\hline & WB+BM- & $5.6 \pm 0.7$ & $5.5 \pm 0.5$ & & & & & & 020 \\
\hline & $\mathrm{WB}-\mathrm{BM}+$ & $5.2 \pm 0.7$ & $5.4 \pm 0.5$ & & & & & & 0.28 \\
\hline & $\mathrm{WB}+\mathrm{BM}+$ & $5.6 \pm 0.6$ & $5.7 \pm 0.7$ & & & & & & \\
\hline
\end{tabular}

${ }^{\mathrm{a}}$ All values are mean $\pm \mathrm{SD}, n=15$ in all groups. 
Table 8. Fecal SCFA concentrations of subjects at baseline and week $4 .^{\text {a }}$

\begin{tabular}{|c|c|c|c|c|c|c|c|c|c|}
\hline \multirow{3}{*}{ Phylum } & \multirow{3}{*}{ Group } & \multirow{3}{*}{ Baseline } & \multirow{3}{*}{ Week 4} & \multicolumn{6}{|c|}{$p$-Value (Two-Way ANOVA) } \\
\hline & & & & \multicolumn{2}{|c|}{ WB } & \multicolumn{2}{|c|}{$\mathbf{B M}$} & \multicolumn{2}{|c|}{$\mathbf{W B} \times \mathbf{B M}$} \\
\hline & & & & Baseline & Week 4 & Baseline & Week 4 & Baseline & Week 4 \\
\hline \multirow{4}{*}{$\begin{array}{c}\text { Acetate } \\
\text { (mg/g feces) }\end{array}$} & WB-BM- & $2.18 \pm 1.42$ & $1.96 \pm 1.10$ & \multirow{4}{*}{0.60} & \multirow{4}{*}{0.04} & \multirow{4}{*}{0.42} & \multirow{4}{*}{0.39} & \multirow{4}{*}{0.35} & \multirow{4}{*}{0.90} \\
\hline & $\mathrm{WB}+\mathrm{BM}-$ & $2.30 \pm 0.88$ & $2.48 \pm 0.98$ & & & & & & \\
\hline & $\mathrm{WB}-\mathrm{BM}+$ & $2.73 \pm 1.17$ & $2.16 \pm 0.97$ & & & & & & \\
\hline & $\mathrm{WB}+\mathrm{BM}+$ & $2.26 \pm 1.19$ & $2.74 \pm 0.94$ & & & & & & \\
\hline \multirow{4}{*}{$\begin{array}{l}\text { Propionate } \\
\text { (mg/g feces) }\end{array}$} & $\mathrm{WB}-\mathrm{BM}-$ & $1.09 \pm 0.59$ & $0.90 \pm 0.37$ & \multirow{4}{*}{0.55} & \multirow{4}{*}{0.16} & \multirow{4}{*}{0.80} & \multirow{4}{*}{0.70} & \multirow{4}{*}{0.90} & \multirow{4}{*}{0.43} \\
\hline & $\mathrm{WB}+\mathrm{BM}-$ & $1.02 \pm 0.47$ & $1.16 \pm 0.66$ & & & & & & \\
\hline & $\mathrm{WB}-\mathrm{BM}+$ & $1.14 \pm 0.40$ & $0.95 \pm 0.31$ & & & & & & \\
\hline & $\mathrm{WB}+\mathrm{BM}+$ & $1.04 \pm 0.57$ & $1.02 \pm 0.39$ & & & & & & \\
\hline \multirow{4}{*}{$\begin{array}{l}\text { iso-Butyrate } \\
\text { (mg/g feces) }\end{array}$} & $\mathrm{WB}-\mathrm{BM}-$ & $0.13 \pm 0.08$ & $0.12 \pm 0.06$ & \multirow{4}{*}{0.60} & \multirow{4}{*}{0.66} & \multirow{4}{*}{0.24} & \multirow{4}{*}{0.89} & \multirow{4}{*}{0.77} & \multirow{4}{*}{0.88} \\
\hline & $\mathrm{WB}+\mathrm{BM}-$ & $0.11 \pm 0.08$ & $0.12 \pm 0.07$ & & & & & & \\
\hline & $\mathrm{WB}-\mathrm{BM}+$ & $0.15 \pm 0.11$ & $0.13 \pm 0.07$ & & & & & & \\
\hline & $\mathrm{WB}+\mathrm{BM}+$ & $0.15 \pm 0.09$ & $0.12 \pm 0.06$ & & & & & & \\
\hline \multirow{4}{*}{$\begin{array}{c}n \text {-Butyrate } \\
\text { (mg/g feces) }\end{array}$} & $\mathrm{WB}-\mathrm{BM}-$ & $0.89 \pm 0.86$ & $0.67 \pm 0.25$ & \multirow{4}{*}{0.53} & \multirow{4}{*}{0.05} & \multirow{4}{*}{0.98} & & & \\
\hline & $\mathrm{WB}+\mathrm{BM}-$ & $0.78 \pm 0.53$ & $0.96 \pm 0.62$ & & & & & & \\
\hline & $\mathrm{WB}-\mathrm{BM}+$ & $0.88 \pm 0.47$ & $0.74 \pm 0.36$ & & & & 0.93 & 0.97 & 0.59 \\
\hline & $\mathrm{WB}+\mathrm{BM}+$ & $0.78 \pm 0.54$ & $0.91 \pm 0.47$ & & & & & & \\
\hline & WB-BM- & $4.64 \pm 2.85$ & $3.94 \pm 1.45$ & & & & & & \\
\hline Total SCFA & $\mathrm{WB}+\mathrm{BM}-$ & $4.52 \pm 1.85$ & $4.98 \pm 2.03$ & & & & & & \\
\hline (mg/g feces) & $\mathrm{WB}-\mathrm{BM}+$ & $5.29 \pm 1.72$ & $4.29 \pm 1.63$ & 0.53 & 0.04 & 0.50 & 0.58 & 0.67 & 0.81 \\
\hline & $\mathrm{WB}+\mathrm{BM}+$ & $4.66 \pm 2.32$ & $5.12 \pm 1.61$ & & & & & & \\
\hline
\end{tabular}


Table 9. Concentrations of fecal putrefaction products in stool samples obtained at baseline and week 4. ${ }^{\text {a }}$

\begin{tabular}{|c|c|c|c|c|c|c|c|c|c|}
\hline \multirow{3}{*}{ Putrefaction Product } & \multirow{3}{*}{ Group } & \multirow{3}{*}{ Baseline } & \multirow{3}{*}{ Week 4} & \multicolumn{6}{|c|}{$p$-Value (Two-Way ANOVA) } \\
\hline & & & & \multicolumn{2}{|c|}{ WB } & \multicolumn{2}{|c|}{$\mathbf{B M}$} & \multicolumn{2}{|c|}{$\mathbf{W B} \times \mathbf{B M}$} \\
\hline & & & & Baseline & Week 4 & Baseline & Week 4 & Baseline & Week 4 \\
\hline $\begin{array}{l}\text { Ammonium } \\
(\mathrm{mg} / \mathrm{g})\end{array}$ & $\begin{array}{l}\mathrm{WB}-\mathrm{BM}- \\
\mathrm{WB}+\mathrm{BM}- \\
\mathrm{WB}-\mathrm{BM}+ \\
\mathrm{WB}+\mathrm{BM}+\end{array}$ & $\begin{array}{l}0.5 \pm 0.2 \\
0.4 \pm 0.2 \\
0.5 \pm 0.3 \\
0.5 \pm 0.4\end{array}$ & $\begin{array}{l}0.5 \pm 0.2 \\
0.5 \pm 0.2 \\
0.5 \pm 0.2 \\
0.4 \pm 0.2\end{array}$ & 0.777 & 0.872 & 0.568 & 0.701 & 0.367 & 0.892 \\
\hline $\begin{array}{c}p \text {-Cresol } \\
(\mu \mathrm{g} / \mathrm{g})\end{array}$ & $\begin{array}{l}\mathrm{WB}-\mathrm{BM}- \\
\mathrm{WB}+\mathrm{BM}- \\
\mathrm{WB}-\mathrm{BM}+ \\
\mathrm{WB}+\mathrm{BM}+\end{array}$ & $\begin{aligned} 75.8 & \pm 67.4 \\
53.7 & \pm 58.9 \\
113.5 & \pm 110.1 \\
70.7 & \pm 72.3\end{aligned}$ & $\begin{array}{l}59.6 \pm 57.3 \\
41.8 \pm 51.2 \\
86.1 \pm 60.9 \\
45.6 \pm 42.0\end{array}$ & 0.129 & 0.043 & 0.191 & 0.284 & 0.616 & 0.416 \\
\hline $\begin{array}{l}\text { Indole } \\
(\mu \mathrm{g} / \mathrm{g})\end{array}$ & $\begin{array}{l}\mathrm{WB}-\mathrm{BM}- \\
\mathrm{WB}+\mathrm{BM}- \\
\mathrm{WB}-\mathrm{BM}+ \\
\mathrm{WB}+\mathrm{BM}+\end{array}$ & $\begin{array}{l}46.7 \pm 30.8 \\
25.6 \pm 19.8 \\
47.1 \pm 39.5 \\
36.3 \pm 22.9\end{array}$ & $\begin{array}{l}33.7 \pm 23.4 \\
21.6 \pm 12.4 \\
35.0 \pm 24.0 \\
26.8 \pm 22.6\end{array}$ & 0.040 & 0.070 & 0.459 & 0.546 & 0.503 & 0.720 \\
\hline $\begin{array}{l}\text { Total putrefaction products } \\
\text { (except ammonium) } \\
(\mu \mathrm{g} / \mathrm{g})\end{array}$ & $\begin{array}{l}\mathrm{WB}-\mathrm{BM}- \\
\mathrm{WB}+\mathrm{BM}- \\
\mathrm{WB}-\mathrm{BM}+ \\
\mathrm{WB}+\mathrm{BM}+\end{array}$ & $\begin{array}{c}134.4 \pm 92.1 \\
89.6 \pm 74.1 \\
174.6 \pm 161.4 \\
121.4 \pm 91.0\end{array}$ & $\begin{array}{c}102.2 \pm 67.9 \\
72.9 \pm 63.8 \\
127.5 \pm 83.7 \\
81.5 \pm 50.0\end{array}$ & 0.604 & 0.037 & 0.421 & 0.385 & 0.346 & 0.896 \\
\hline
\end{tabular}

${ }^{\text {a }}$ All values are mean $\pm \mathrm{SD}, n=15$ in all groups except $n=14$ in the $\mathrm{WB}-\mathrm{BM}+$ group. 


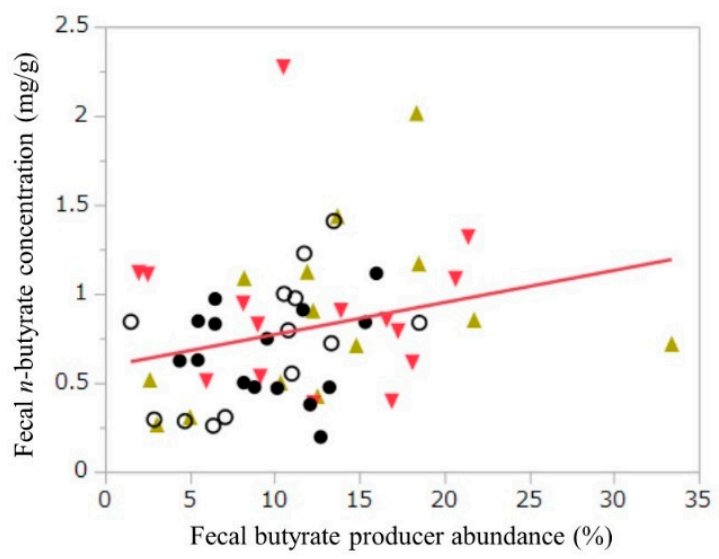

Figure 5. Relationship between the abundance of butyrate producers and the fecal concentration of butyrate at week 4. $r=0.32$ (Spearman's rank correlation coefficient), $p<0.05$. $\bullet \mathrm{WB}-\mathrm{BM}-$, $\mathrm{WB}-\mathrm{BM}+, \boldsymbol{\mathrm { NB }}+\mathrm{BM}-, \mathbf{\nabla} \mathrm{WB}+\mathrm{BM}+$

\section{Discussion}

In the present work, we studied the effect of dietary supplementation with cereal bars containing WB and/or BM in healthy adult human volunteers. We investigated which dietary fiber source would produce more favorable changes in fecal variables (e.g., higher butyrate, lower phenols, and lower ammonia). We also investigated whether combining WB with BM would modify the fecal microbiota more favorably than supplementation with WB or BM alone. The results indicated that WB increased the fecal concentration of butyrate through increasing the abundance of butyrate-producing bacteria in the gut except for the genus Anaerostipes. A previous study examined which bacteria contribute to butyrate production in the gut and concluded that the major butyrate-producing bacteria isolated from the human colon belong to the Clostridium coccoides (XIVa) and Clostridium leptum (IV) clusters [37]. In our study, we mainly detected butyrate producers in the Clostridium XIVa cluster, such as Roseburia, Anaerostipes, and Coprococcus, and in the Clostridium IV cluster, such as Faecalibacterium. Amylase-pretreated WB as the sole added energy source was previously reported to be well fermented by butyrate producers in human intestinal microbial communities in anaerobic fermentors [14]. In an experiment using weaned male piglets, the intake of WB increased the cecal concentrations of acetate and butyrate [13]. These findings are consistent with our results. Arabinoxylan, which is an almost-insoluble fiber linked with ferulic acid, is a main component of dietary fiber in WB [9]. It was reported that the release of ferulic acid via human bacterial degradation promoted arabinoxylan solubilization and degradation [14]. Degradation products of arabinoxylan, such as arabinoxylan oligosaccharides, were reported to increase fecal butyrate concentrations and lower the urinary excretion of phenols and $p$-cresol [38]. In our study, with both of WB+BM- and $\mathrm{WB}+\mathrm{BM}+$, the daily intake of arabinoxylan from $\mathrm{WB}$ was $2.1 \mathrm{~g} /$ day, insoluble dietary fiber was $4.8 \mathrm{~g} /$ day, and total dietary fiber was $5.1 \mathrm{~g} /$ day. In a prior study, the intake of bread containing $2.14 \mathrm{~g} /$ day arabinoxylan oligosaccharides increased the fecal concentrations of butyrate and total SCFAs [38]. The intake of more than $2.1 \mathrm{~g} /$ day arabinoxylan from WB might effectively increased the fecal concentration of butyrate by increasing the abundance of butyrate producers in the gut. Further intervention studies are needed to elucidate the adequate dose of arabinoxylan.

It has been reported that butyrate exerted a preventive effect against cancer of the colon by promoting cell differentiation, cell-cycle arrest, and apoptosis of transformed colonocytes [38]. Butyrate also inhibited the enzyme histone deacetylase and decreased the transformation of primary bile acids to secondary ones as a result of colonic acidification [38]. Therefore, a significant increase in SCFA production, specifically butyrate, caused by WB intake may result in a protective effect against colonic disorders. 
Bacteria related to Anaerostipes caccae [39] within the C. coccoides cluster were shown to be able to convert acetate and lactate into butyrate, in addition to producing butyrate from carbohydrates $[14,40]$. In our study, the abundance of Anaerostipes was decreased by WB intake. The reason for this is unknown, but it may be related to changes in other bacterial populations such as those of the major butyrate producers Faecalibacterium and Roseburia.

No diversity indices were affected by WB and BM intake. This finding is consistent with a recent systematic review and meta-analysis that concluded that fiber intervention has no significant effect on $\alpha$-diversity [41]. Although a lack of fermentable fiber intake decreases diversity indices, an increase in fermentable fiber intake may not change diversity indices in healthy subjects who already consume some fermentable fiber in their staple diets before supplementation.

The abundances of most butyrate-producing genera at baseline were significantly lower in the BM groups than in the non-BM groups, whereas significant differences were not observed at week 4 .

Changes in the abundance of Clostridium were significantly more pronounced in the BM groups than in the non-BM groups, and changes in the abundances of most butyrate-producing genera were also more prominent in the BM groups than in the non-BM groups (although these changes were not statistically significant). Therefore, BM might have affected the abundance of some butyrate-producing genera even though there were no variations in the abundance of most butyrate-producing genera.

The differential effects of WB and BM intake on fecal butyrate concentrations and butyrate producer populations might have been associated with differences between these fiber sources in intestinal transit time and fermentation speed. In a previous study, purified and semi-purified polysaccharides characteristic of cereals were fermented in vitro with a pig fecal inoculum, using the cumulative gas production technique, to examine the kinetics and end-products of fermentation after $48 \mathrm{~h}$ [42]. It was shown that barley $\beta$-glucan was fermented rapidly if soluble, while insoluble arabinoxylan was fermented more slowly. Fructan is fermented more rapidly than barley $\beta$-glucan. Therefore, fructan and $\beta$-glucan in BM are fermented rapidly in the proximal colon and SCFAs might be absorbed at that site. The fructan content in the BM material was $9.0 \mathrm{~g} / 100 \mathrm{~g}$, but the fructan content in the test foods was not analyzed. The contribution of fructan in BM to the changes observed in microbiota and fecal metabolites was unknown in this study. It is important to note that fecal SCFA concentrations are the net result of production and absorption, and it is therefore difficult to evaluate the total SCFA production. The acceleration of the whole-gut transit time by WB may also have contributed to the increase in the concentration of fecal SCFAs in the WB groups [43]. Human studies have indicated that SCFA production is increased with a short transit time, while longer transit times are associated with a shift from carbohydrate to protein fermentation $[44,45]$. By contrast, the concentrations of $p$-cresol and total putrefaction products except ammonia were significantly lower in the WB groups than in the non-WB groups. The generation of putrefaction products might have been inhibited by a decrease in fecal $\mathrm{pH}$ owing to an increase in the concentration of SCFAs. However, the concentration of SCFAs was relatively low at week 4 as compared to baseline. Increases in fecal bulk and water content caused by insoluble dietary fiber intake might have diluted the fecal concentration of SCFAs.

A significant interactive effect of WB and BM on the abundances of phylum Bacteroidetes and genus Bacteroides was observed at week 4. Bacteroidetes and Firmicutes are the major bacterial phyla in the colonic microbiota. Significant decreases in the relative proportions of Bacteroidetes and Firmicutes have been observed in older adults as compared to younger adults [46]. A study on the fecal bacteria in healthy old volunteers living in the local community; old, hospitalized patients; and old, hospitalized patients receiving antibiotic treatment [47] exhibited a decrease in the abundance of the Bacteroides-Prevotella group in the old, hospitalized patients. IgA helps to neutralize the toxins produced by microbes and prevents the adherence of the microbiota to the intestinal lumen. The induction of secretory IgA appears to be more efficient in the presence of Bacteroidetes [48]. Taken together, the combined effect of WB and BM in increasing the abundance of the phylum Bacteroidetes can be expected to be beneficial for preventing age-related colonic disorders. 
There are several potential limitations of our study that may partly explain the lack of an observed effect of the combination of WB and BM on the concentrations of fecal metabolites. First, the relatively small sample size for each arm may have contributed to the observed non-significant results. Secondly, the relatively low $\beta$-glucan intake from $\mathrm{BM}$ was $0.7 \mathrm{~g} /$ day with both of $\mathrm{WB}-\mathrm{BM}+$ and $\mathrm{WB}+\mathrm{BM}+$, and may not have been sufficient to cause a significant increase in fecal metabolite concentrations. Finally, the intervention period was relatively short. Longer intervention studies may be needed to elucidate the effects of the combination of WB and BM on colonic health.

\section{Conclusions}

The consumption of whole grains has been proposed to improve colonic health. In this study, we investigated the influence of the dietary fiber sources WB and BM on fecal microbiota composition, SCFA production, and fecal putrefaction products in healthy Japanese adults. WB was associated with elevated concentrations of fecal SCFAs including butyrate owing to an increase in the abundance of butyrate-producing bacteria in the colon. Additionally, the combination of WB and BM was associated with an altered composition of the microbiota, favoring an increase in the abundance of the genus Bacteroides.

Supplementary Materials: The following are available online at http:/ / www.mdpi.com/2072-6643/10/12/1980/ s1. Supplementary Table S1: Effects of wheat bran and BARLEYmax intake on body weight and body mass index, body fat, and blood pressure at baseline and after 4 weeks. Supplementary Table S2: Effects of wheat bran and BARLEYmax on serum biochemistry at baseline and after 4 weeks. Supplementary Table S3: Effects of wheat bran and BARLEYmax on blood markers. Supplementary Table S4: Changes in relative abundances of bacteria phyla in fecal samples between baseline and week 4. Supplementary Table S5: Changes in relative abundances of selected bacteria genera in fecal samples between baseline and week 4. Supplementary Table S6: Changes in fecal SCFA and organic acid concentrations of subjects between baseline and week 4. Supplementary Table S7: Changes in concentrations of fecal putrefaction products in stool samples between baseline and week 4 .

Author Contributions: S.A. and S.F. designed the research; S.A. conducted the research; F.N. and S.F. analyzed the data; S.A. wrote the paper. S.A. had primary responsibility for the final content. All authors read and approved the final manuscript.

Funding: This research received research support from Kellogg (Japan) G.K.

Acknowledgments: The authors acknowledge funding support from Kellogg (Japan) G.K. We would like to thank TechnoSuruga Laboratory for technical support. The authors wish to thank members of TechnoSuruga Laboratory for their help in generating the 16SrRNA gene data.

Conflicts of Interest: The authors declare no conflict of interest. The research was supported by a grant from Kellogg (Japan) G.K., who had no role in the design of the study; in the collection, analyses, or interpretation of data; in the writing of the manuscript, and in the decision to publish the results.

\section{References}

1. Ma, Y.; Hu, M.; Zhou, L.; Ling, S.; Li, Y.; Kong, B.; Huang, P. Dietary fiber intake and risks of proximal and distal colon cancers: A meta-analysis. Medicine 2018, 97, e11678. [CrossRef] [PubMed]

2. Kritchevsky, D. Epidemiology of fibre, resistant starch and colorectal cancer. Eur. J. Cancer Prev. 1995, 4, 345-352. [CrossRef] [PubMed]

3. Giovannucci, E.; Willett, W.C. Dietary factors and risk of colon cancer. Ann. Med. 1994, 26, 443-452. [CrossRef] [PubMed]

4. Williams, P.G. The benefits of breakfast cereal consumption: A systematic review of the evidence base. Adv. Nutr. 2014, 5, 636S-673S. [CrossRef]

5. Sonnenburg, E.D.; Smits, S.A.; Tikhonov, M.; Higginbottom, S.K.; Wingreen, N.S.; Sonnenburg, J.L. Diet-induced extinctions in the gut microbiota compound over generations. Nature 2016, 529, 212-215. [CrossRef] [PubMed]

6. Petersen, C.; Round, J.L. Defining dysbiosis and its influence on host immunity and disease. Cell. Microbiol. 2014, 16, 1024-1033. [CrossRef] [PubMed]

7. Buttó, L.F.; Schaubeck, M.; Haller, D. Mechanisms of microbe-host interaction in Crohn's disease: Dysbiosis vs. pathobiont selection. Front. Immunol. 2015, 6, 555. [CrossRef]

8. Stevenson, L.; Phillips, F.; O'Sullivan, K.; Walton, J. Wheat bran: Its composition and benefits to health, a European perspective. Int. J. Food Sci. Nutr. 2012, 63, 1001-1013. [CrossRef] 
9. Rosa-Sibakova, N.; Poutanen, K.; Micard, V. How does wheat grain, bran and aleurone structure impact their nutritional and technological properties? Trends Food Sci. Technol. 2015, 41, 118-134. [CrossRef]

10. Bijkerk, C.J.; Muris, J.W.M.; Knottnerus, J.A.; Hoes, A.W.; de Wit, N.J. Systematic review: The role of different types of fibre in the treatment of irritable bowel syndrome. Aliment. Pharmacol. Ther. 2004, 19, 245-251. [CrossRef]

11. Vuksan, V.; Jenkins, A.L.; Jenkins, D.J.; Rogovik, A.L.; Sievenpiper, J.L.; Jovanovski, E. Using cereal to increase dietary fiber intake to the recommended level and the effect of fiber on bowel function in healthy persons consuming North American diets. Am. J. Clin. Nutr. 2008, 88, 1256-1262. [PubMed]

12. Hamer, H.M.; Jonkers, D.; Venema, K.; Vanhoutvin, S.; Troost, F.J.; Brummer, R.J. The role of butyrate on colonic function. Aliment. Pharmacol. Ther. 2008, 27, 104-119. [CrossRef] [PubMed]

13. Chen, H.; Wang, W.; Degroote, J.; Possemiers, S.; Chen, D.; De Smet, S.; Michiels, J. Arabinoxylan in wheat is more responsible than cellulose for promoting intestinal barrier function in weaned male piglets. J. Nutr. 2015, 145, 51-58. [CrossRef] [PubMed]

14. Duncan, S.H.; Russell, W.R.; Quartieri, A.; Rossi, M.; Parkhill, J.; Walker, A.W.; Flint, H.J. Wheat bran promotes enrichment within the human colonic microbiota of butyrate-producing bacteria that release ferulic acid. Environ. Microbiol. 2016, 18, 2214-2225. [CrossRef] [PubMed]

15. Hughes, S.A.; Shewry, P.R.; Gibson, G.R.; McCleary, B.V.; Rastall, R.A. In vitro fermentation of oat and barley derived $\beta$-glucans by human faecal microbiota. FEMS Microbiol. Ecol. 2008, 64, 482-493. [CrossRef] [PubMed]

16. Nishimura, A.; Kitazono, E.; Imose, K.; Urita, S.; Matsui, T. Effect of functional barley BARLEYmax (Tantangara) on intestinal regulation: A double-blind, randomized, placebo-controlled parallel group comparison clinical study. Jpn. Pharmacol. Ther. 2017, 45, 1047-1055.

17. Henningsson, A.M.; Björck, I.M.; Nyman, E.M. Combinations of indigestible carbohydrates affect short-chain fatty acid formation in the hindgut of rats. J. Nutr. 2002, 132, 3098-3104. [CrossRef] [PubMed]

18. Muir, J.G.; Yeow, E.G.W.; Keogh, J.; Pizzey, C.; Bird, A.R.; Sharpe, K.; O’Dea, K.; Macrae, F.A. Combining wheat bran with resistant starch has more beneficial effects on fecal indexes than does wheat bran alone. Am. J. Clin. Nutr. 2004, 79, 1020-1028. [CrossRef]

19. Xiao, J.; Kondo, S.; Odamaki, T.; Miyaji, K.; Yaeshima, T.; Iwatsuki, K.; Togashi, H.; Benno, Y. Effect of yogurt containing Bifidobacterium longum BB536 on the defecation frequency and fecal characteristics of healthy adults: A double-blind cross over study. Jpn. J. Lact. Acid Bact. 2007, 18, 31-36. [CrossRef]

20. Lee, S.C.; Rodriguez, F.; Storey, M.; Farmakalidis, E.; Prosky, L. Determination of soluble and insoluble dietary fiber in psyllium containing cereal products. J. AOAC Int. 1995, 78, 724-729.

21. McCleary, B.V.; Codd, R. Measurement of 1-3, 1-4- $\beta$-D-glucan in barley and oats: A streamlined enzymic procedure. J. Sci. Food Agric. 1991, 55, 303-312. [CrossRef]

22. McCleary, B.V.; Monaghan, D.A. Measurement of resistant starch. J. AOAC Int. 2002, 85, 665-675.

23. Cyran, M.R.; Dynkowska, W.M. Mode of endosperm and wholemeal arabinoxylans solubilisation during rye breadmaking: Genotypic diversity in the level, substitution degree and macromolecular characteristics. Food Chem. 2014, 145, 356-364. [CrossRef] [PubMed]

24. Standard Tables of Food Composition in Japan, Seventh Revised Version (2015). Available online: http:/ / www.mext.go.jp/en/policy/science_technology/policy/title01/detail01/sdetail01/sdetail01/ 1385122.htm (accessed on 28 October 2017).

25. Takahashi, S.; Tomita, J.; Nishioka, K.; Hisada, T.; Nishijima, M. Development of a prokaryotic universal primer for simultaneous analysis of Bacteria and Archaea using next-generation sequencing. PLoS ONE 2014, 9, e105592. [CrossRef] [PubMed]

26. Muyzer, G.; de Waal, E.C.; Uitterlinden, A.G. Profiling of complex microbial populations by denaturing gradient gel electrophoresis analysis of polymerase chain reaction-amplified genes coding for 16S rRNA. Appl. Environ. Microbiol. 1993, 59, 695-700. [PubMed]

27. Caporaso, J.G.; Lauber, C.L.; Walters, W.A.; Berg-Lyons, D.; Lozupone, C.A.; Turnbaugh, P.J.; Fierer, N.; Knight, R. Global patterns of $16 \mathrm{~S}$ rRNA diversity at a depth of millions of sequences per sample. Proc. Natl. Acad. Sci. USA 2011, 108 (Suppl. 1), 4516-4522. [CrossRef] [PubMed]

28. Erik, A. EA-Utils "Command-Line Tools for Processing Biological Sequencing Data". Available online: http:/ / code.google.com/p/ea-utils (accessed on 30 September 2018).

29. Available online: http://hannonlab.cshl.edu/fastx_toolkit/ (accessed on 31 October 2018). 
30. Caporaso, J.G.; Kuczynski, J.; Stombaugh, J.; Bittinger, K.; Bushman, F.D.; Costello, E.K.; Fierer, N.; Peña, A.G.; Goodrich, J.K.; Gordon, J.I. QIIME allows analysis of high-throughput community sequencing data. Nat. Methods 2010, 7, 335-336. [CrossRef] [PubMed]

31. Wang, Q.; Garrity, G.M.; Tiedje, J.M.; Cole, J.R. Naïve Bayesian classifier for rapid assignment of rRNA sequences into the new bacterial taxonomy. Appl. Environ. Microbiol. 2007, 73, 5261-5267. [CrossRef]

32. Available online: http://rdp.cme.msu.edu/classifier/ (accessed on 31 October 2018).

33. Available online: http://greengenes.secondgenome.com/ (accessed on 31 October 2018).

34. Higashimura, Y.; Naito, T.; Takagi, T.; Uchida, K.; Mizushima, K.; Ushiroda, C.; Ohnogi, H.; Kudo, Y.; Tasui, M.; Inui, S.; et al. Protective effect of agaro-oligosaccharides on gut dysbiosis and colon tumorigenesis in high-fat diet-fed mice. Am. J. Physiol. Gastrointest. Liver Physiol. 2016, 310, G367-G375. [CrossRef]

35. Zhang, H.; Zhou, F.; Ji, B.; Nout, R.M.J.; Fang, Q.; Yang, Z. Determination of organic acids evolution during apple cider fermentation using an improved HPLC analysis method. Eur. Food Res. Technol. 2008, 227, 1183-1190. [CrossRef]

36. Louis, P.; Flint, H.J. Diversity, metabolism and microbial ecology of butyrate-producing bacteria from the human large intestine. FEMS Microbiol. Lett. 2009, 294, 1-8. [CrossRef] [PubMed]

37. Damen, B.; Cloetens, L.; Broekaert, W.F.; François, I.; Lescroart, O.; Trogh, I.; Arnaut, F.; Welling, G.W.; Wijffels, J.; Delcour, J.A.; et al. Consumption of breads containing in situ-produced arabinoxylan oligosaccharides alters gastrointestinal effects in healthy volunteers. J. Nutr. 2012, 142, 470-477. [CrossRef] [PubMed]

38. Wong, J.M.; de Souza, R.; Kendall, C.W.; Emam, A.; Jenkins, D.J. Colonic health: Fermentation and SCFA. Clin. Gastroenterol. 2006, 40, 235-243. [CrossRef]

39. Schwiertz, A.; Hold, G.I.; Duncan, S.H.; Gruhl, B.; Collins, M.D.; Lawson, P.A.; Flint, H.J.; Blaut, M. Anaerostipes caccae gen. nov., sp. nov., a new saccharolytic acetate-utilising butyrate-producing bacterium from human faeces. Syst. Appl. Microbiol. 2002, 25, 46-51. [CrossRef] [PubMed]

40. Sato, T.; Matsumoto, K.; Okumura, T.; Yokoi, W.; Naito, E.; Yoshida, Y.; Nomoto, K.; Ito, M.; Sawada, H. Isolation of lactate-utilising butyrate-producing bacteria from human feces and in vivo administration of Anaerostipes caccae strain L2 and galacto-oligosaccharides in a rat model. FEMS Microbiol. Ecol. 2008, 66, 528-536. [CrossRef] [PubMed]

41. So, D.; Whelan, K.; Rossi, M.; Morrison, M.; Holtmann, G.; Kelly, J.T.; Shanahan, E.R.; Staudacher, H.M.; Campbell, K.L. Dietary fiber intervention on gut microbiota composition in healthy adults: A systematic review and meta-analysis. Am. J. Clin. Nutr. 2018, 107, 965-983. [CrossRef] [PubMed]

42. Williams, B.A.; Mikkelsen, D.; le Paih, L.; Gidley, M.J. In vitro fermentation kinetics and end-products of cereal arabinoxylans and (1,3;1,4)- $\beta$-glucans by porcine faeces. J. Cereal Sci. 2011, 53, 53-58. [CrossRef]

43. De Vries, J.; Miller, P.E.; Verbeke, K. Effects of cereal fiber on bowel function: A systematic review of intervention trials. World J. Gastroenterol. 2015, 21, 8952-8963. [CrossRef] [PubMed]

44. Lewis, S.J.; Heaton, K.W. Increasing butyrate concentration in the distal colon by accelerating intestinal transit. Gut 1997, 41, 245-251. [CrossRef] [PubMed]

45. Roager, H.M.; Hansen, L.B.; Bahl, M.I.; Frandsen, H.L.; Carvalho, V.; Gobel, R.J.; Dalgaard, M.D.; Plichta, D.R.; Sparholt, M.H.; Vestergaard, H.; et al. Colonic transit time is related to bacterial metabolism and mucosal turnover in the gut. Nat. Microbiol. 2016, 1, 16093. [CrossRef] [PubMed]

46. Mariat, D.; Firmesse, O.; Levenez, F.; Guimarăes, V.D.; Sokol, H.; Doré, J.; Corthier, G.; Furet, J.P. The Firmicutes/Bacteroidetes ratio of the human microbiota changes with age. BMC Microbiol. 2009, 9, 123. [CrossRef] [PubMed]

47. Vemuri, R.; Gundamaraju, R.; Shastri, M.D.; Shukla, S.D.; Kalpurath, K.; Ball, M.; Tristram, S.; Shankar, E.M.; Ahuja, K.; Eri, R. Gut microbial changes, interactions, and their implications on human lifecycle: An ageing perspective. BioMed Res. Int. 2018, 2018, 4178607. [CrossRef] [PubMed]

48. Mantis, N.J.; Rol, N.; Corthésy, B. Secretory IgA's complex roles in immunity and mucosal homeostasis in the gut. Mucosal Immunol. 2011, 4, 603-611. [CrossRef] [PubMed]

(C) 2018 by the authors. Licensee MDPI, Basel, Switzerland. This article is an open access article distributed under the terms and conditions of the Creative Commons Attribution (CC BY) license (http:/ / creativecommons.org/licenses/by/4.0/). 